\title{
Estratigrafía, paleoambientes y correlación del Paleozoico Superior en la localidad Río Francia, Cuenca Paganzo, Argentina
}

\author{
*Gustavo Correa ${ }^{1}$, Pedro Raúl Gutiérrez ${ }^{2}$ \\ ${ }^{I}$ Instituto y Museo de Ciencias Naturales, Universidad Nacional de San Juan-CIGEOBIO, CONICET. Av. España 400 norte, San \\ Juan, Argentina. \\ gcorrea@unsj.edu.ar \\ 2 CONICET (Consejo Nacional de Investigaciones Científicas y Técnicas), Sección Paleopalinología, Museo Argentino de Ciencias \\ Naturales Bernardino Rivadavia, Av. Ángel Gallardo 470, C1405DJR, Buenos Aires, Argentina. \\ pedroraulgutierrez@gmail.com \\ *Autor para correspondencia: gcorrea@unsj.edu.ar
}

\begin{abstract}
RESUMEN. Las formaciones Tupe y Patquía son conocidas por sus depósitos marinos, deltaicos, fluviales y eólicos, los cuales registran diferentes eventos del Paleozoico tardío en la Cuenca Paganzo, en el centro oeste de Argentina. En el área del río Francia (provincia de San Juan, Argentina), estas unidades adquieren una especial relevancia por ubicarse en un lugar estratégico de conexión con las secuencias sedimentarias más australes en la Cuenca Paganzo sobre la precordillera Central. La Formación Tupe (que por datos palinológicos representaría el intervalo Serpukhoviano tardíoGzheliano medio) totaliza un espesor mínimo de $140 \mathrm{~m}$ de pelitas bioturbadas con un porcentaje menor de areniscas gruesas a finas intercaladas, las cuales en este trabajo se agrupan en 3 asociaciones de facies: I lagoon, II isla barrera y III shoreface. La Formación Patquía (a partir de datos palinológicos, en esta localidad, de edad cisuraliana) es una típica sucesión de estratos rojos con depósitos de areniscas finas entrecruzadas, y alternancia de areniscas con pelitas. En ella fueron diferenciadas 3 asociaciones de facies: IV fluvial anastomosado, V eólico y VI barreal. Un análisis de correlación entre estas formaciones y sus equivalentes litoestratigráficos brindó posibles escenarios para el sector occidental de la Cuenca Paganzo, mostrando en estas latitudes un lineamiento de unidades con ambientes costeros para la Formación Tupe y equivalentes. En cambio para la Formación Patquía y sus equivalentes, se muestra una progresiva continentalización de norte a sur.
\end{abstract}

Palabras clave: Formación Tupe, Formación Patquía, Cuenca Paganzo, Precordillera, Paleogeografía.

\begin{abstract}
Stratigraphy, paleoenvironment and correlation of the Upper Paleozoic at Río Francia locality, Paganzo Basin, Argentina. The Tupe and Patquía formations are known for their marine, deltaic, river, and eolian deposits that record different Late Paleozoic events in the Paganzo Basin. However, in the area of the Río Francia (Province of San Juan, Argentina), these units are relevant because they are located in a strategic place of connection with the southernmost sedimentary sequences in the Paganzo Basin on the Central Precordillera. The Tupe Formation (which by palynological data would represent the late Serpukhovian-Gzhelian interval) has a minimum thickness of $140 \mathrm{~m}$ of bioturbed mudstones with a minor percentage of coarse to fine sandstones intercalated. In this work they are grouped into 3 facies associations: I lagoon; II barrier island and III shoreface. The Patquía Formation (from palynological data, in this locality, of Cisuralian in age), it is a typical succession of red beds with deposits of fine -grained sandstones with cross-bedding, and alternation of sandstones with mudstones. 3 facies associations were differentiated: IV anastomosed fluvial; V eolian and VI playa lake. A correlation analysis between these formations and their lithostratigraphic equivalents provided possible scenarios for the western sector of the Paganzo Basin, showing a lineament of units with coastal environment features for the Tupe Formation and equivalents at these latitudes. On the other hand, the Patquía Formation and their equivalents display a progressive continentalization from north to south.
\end{abstract}




\section{Introducción}

La Cuenca Paganzo, ubicada en el centro oeste de Argentina, se desarrolló en el lapso desde el Carbonífero al Pérmico y abarca entre los 28 y los $33^{\circ} \mathrm{S}$ y desde los 66 a los $70^{\circ} \mathrm{O}$ y tiene una superficie de alrededor de $140.000 \mathrm{~km}^{2}$ (Net y Limarino, 2006) (Fig. 1A). Durante el Carbonífero, el alto estructural de la Protoprecordillera (Amos y Rolleri, 1965; Salfity y Gorustovich, 1983; González Bonorino, 1991; Henry et al., 2010) habría separado la Cuenca Paganzo de la Cuenca Calingasta-Uspallata, ubicada al oeste de la primera (Fig. 1). Este elemento positivo habría funcionado como barrera entre ambas, aunque con sectores de comunicación. Estas 2 cuencas conformaban un sistema depositacional, que puede dividirse en 3 sectores con distinta influencia marina. Al este, el depocentro suroriental de la Cuenca Paganzo, emplazado en el basamento pampeano, se caracteriza por tener un ambiente de depositación predominantemente continental (Fig. 1). El depocentro central abarca las secuencias sedimentarias mayoritariamente emplazadas en la actual precordillera, incluye los afloramientos analizados en este trabajo, con paleoambientes sedimentarios mixtos (Salfity y Gorustovich, 1983). El depocentro occidental, al oeste (Fig. 1), está representado por la Cuenca Calingasta-Uspallata que posee paleoambientes sedimentarios predominantemente marinos, que fueron progresivamente reemplazados por el vulcanismo Choiyoi en el Pérmico (Fernández Sevesso et al., 1993; Limarino et al., 1996; Llambías, 1999; Spalletti y Limarino, 2017).

El inicio de la sedimentación neopaleozoica, en la Cuenca Paganzo, se encuentra representada por el registro de una de las grandes glaciaciones gondwánicas, la correspondiente a las sucesiones glacigénicas del límite Misisipiano-Pensilvaniano, (Gulbranson et al., 2010). La cuenca registra depósitos de tillitas, diamictitas resedimentadas, varves que forman ritmitas y, más comúnmente, pelitas con dropstones (Limarino y Gutiérrez, 1990; López Gamundí y Martínez, 2000; Marenssi et al., 2005; Limarino et al., 2014). Bajo la denominación actual, estas sucesiones comprenden los afloramientos de la Formación Guandacol y sus equivalentes.

Por sobre los registros del evento glacigénico, en gran parte de la Cuenca Paganzo, se disponen sucesiones de rocas sedimentarias fluviales y deltaicas, separadas por transgresiones marinas en algunos casos, las cuales se asignan a la Formación Tupe y sus equivalentes (Desjardins et al., 2009). Lo más característico de estas unidades son los depósitos de carbón que preservaron restos de plantas atribuidos a la Biozona Nothorhacopteris-Botrychiopsis-Gingophyllum $(N B G)$ y que sirven como niveles guía de correlación regional, debido a que se los puede seguir en casi toda la Cuenca Paganzo. Algunas de estas plantas fósiles brindan información biocronológica (Archangelsky, 1987, 1996; Césari et al., 2011).

En términos generales, por encima de la Formación Tupe y equivalentes, dominan los depósitos de capas rojas correspondientes al evento árido que dominó la Cuenca Paganzo en el Pérmico (Gulbranson et al., 2015). Aquí se destacan las formaciones Patquía, De la Cuesta, La Colina y sus equivalentes. Estas unidades están formadas por depósitos eólicos, fluviales y lacustres efímeros.

Debido a la paleogeografía de la Cuenca Paganzo (Fig. 1A), los depósitos carbonosos más extensos se acumularon en el depocentro oriental (ambientes continentales) y en el sector norte del depocentro central. Esto generó una importante desigualdad histórica en la cantidad de los estudios de índole geológica y paleobotánica. Es decir, provocó que en el sector centro-sur de la precordillera se disponga de escasos trabajos de este tipo en comparación con el resto de la cuenca.

Hasta el momento, la estratigrafía posglaciación en la localidad Río Francia no se ha estudiado en detalle; la mayoría de los estudios en este lugar se enfocaron en los depósitos de la Formación Guandacol (Bercowski y Milana, 1990; Milana y Bercowski, 1990; Perez Loinaze et al., 2014).

El presente trabajo se focaliza en la caracterización estratigráfica y paleoambiental de las formaciones Tupe y Patquía en la localidad Río Francia. Además, se propone una puesta en valor como punto de conexión entre los sectores mejor conocidos de la Cuenca Paganzo y los sectores centro-sur de la precordillera Central. Destacándose, así como un lugar de privilegio para entender cómo fue la distribución paleoambiental en la Cuenca Paganzo, que marca una posible evolución de la línea de costa desde el Pensilvaniano al Cisuraliano.

\section{Antecedentes y marco geológico}

Los afloramientos neopaleozoicos de la quebrada del río Francia (Fig. 1) son conocidos desde los trabajos de Stappenbeck (1910), Bodenbender (1911) 

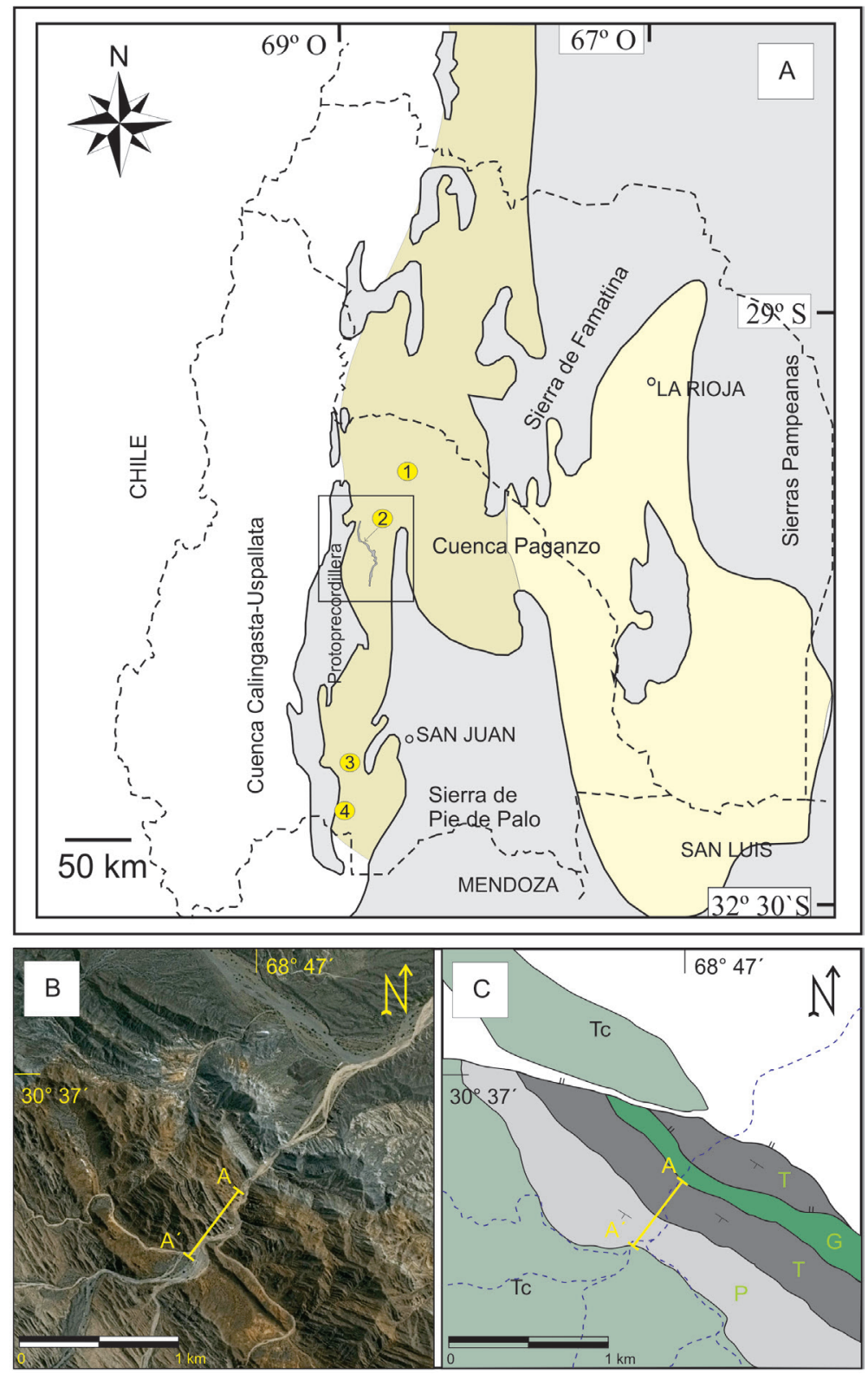

FIG. 1. A. Esquema paleogeográfico de la Cuenca Paganzo, modificado de Salfity y Gorustovich (1983). 1: localidad Huaco; 2: marca la ubicación de la localidad Río Francia; 3: localidad Maradona y 4: localidad Bachongo. Los depocentros explicados en el texto se muestran en amarillo claro (depocentro oriental), amarillo oscuro (depocentro central) y blanco (depocentro occidental o Cuenca Calingasta-Uspallata). B. Detalle de la localidad Río Francia, se destaca la sección A-A' donde se relevó la columna de la figura 2. C. Interpretación de las unidades analizadas. G: Formación Guandacol; T: Formación Tupe; P: Formación Patquía; Tc: Terciario indiferenciado.

y Borrello (1956); aunque recién durante la primera mitad de la década de los 80, Cuerda y Furque (1981) y Bossi y Andreis (1985) les asignaran nombres formales.
Cuerda y Furque (1981) definieron la Formación Río Francia como una secuencia de rocas sedimentarias de $951 \mathrm{~m}$ de espesor, constituida por depósitos continentales formados principalmente por areniscas 
y lutitas subordinadas, con la base truncada por falla (Tabla 1). Esta formación está subdividida en 4 miembros, que se detallan a continuación:

1. Miembro Areniscas Grises (AG), con $83 \mathrm{~m}$ de espesor mínimo, está compuesto principalmente por psamitas con algunas intercalaciones de arcilitas y limolitas carbonosas. En su parte basal, se destaca la presencia de un horizonte de carbón, el cual fue explotado en la antigua mina La Gloria. Hacia arriba son abundantes las areniscas cuarzosas con estratos macizos de $0,5 \mathrm{~m}$ de espesor en promedio y de formas tabulares. Cuerda y Furque (1981) interpretaron este miembro como depositado en un ambiente fluvial con llanura de inundación.

2. Miembro Fangolitas y Limolitas Verdes (FLV), con $114 \mathrm{~m}$ de espesor, caracterizado por una sucesión monótona de fangolitas y limolitas con dropstones y hacia los niveles superiores con numerosas pistas de vermes.
3. Miembro Areniscas Varicolores (AV), compuesto por $340 \mathrm{~m}$ de areniscas grisáceas, rojo ladrillo, violáceas, verdosas y blanquecinas con intercalaciones subordinadas de pelitas de espesores métricos y formas tabulares. En la parte inferior del miembro, Cuerda y Furque (1981), describieron un nivel con Paracalamites sp. y le asignaron un paleoambiente fluvial meandroso con niveles palustres.

4. Miembro Areniscas Rosadas (AR), constituye la parte alta de la Formación Río Francia y subyace en concordancia o discordancia de bajo ángulo a las rocas de la Formación Patquía. Este miembro alcanza un espesor de $414 \mathrm{~m}$ y está compuesto por sucesiones granodecrecientes desde conglomerados en la base, sucedidos por areniscas de forma mayoritaria y algunas veces coronados por pelitas, los cuales se interpretaron como depositados en un paleoambiente fluvial anastomosado.

TABLA 1. ESQUEMA CON LAS DISTINTAS INTERPRETACIONES ESTRATIGRÁFICAS PARA LA SECUENCIA SEDIMENTARIA AFLORANTE EN LA LOCALIDAD RÍO FRANCIA (CUERDA Y FURQUE, 1981; BOSSI Y ANDREIS, 1985; GUTIÉRREZ ET AL., 2010; PEREZ LOINAZE ET AL., 2011).

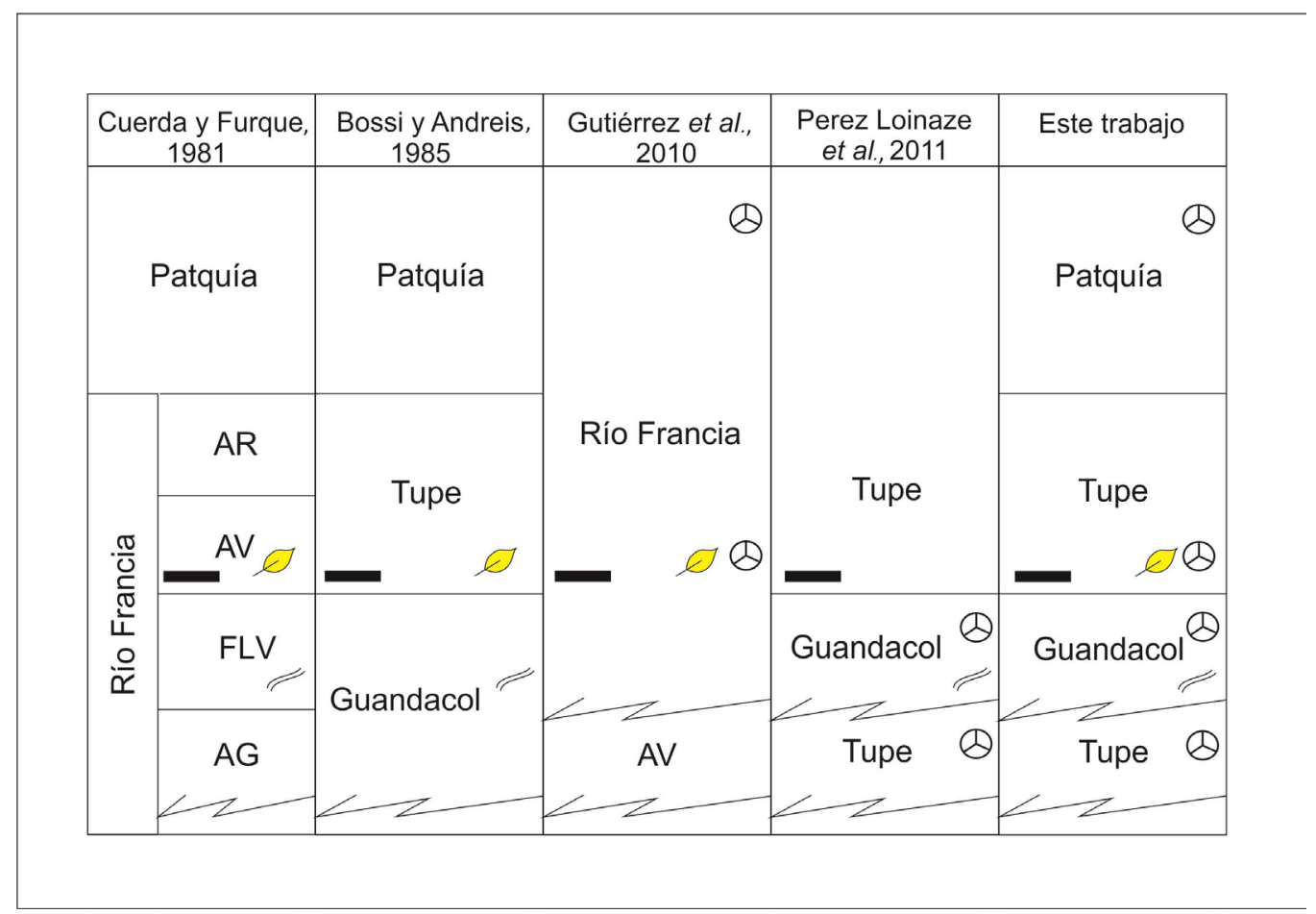

Miembros AG: areniscas grises, FLV: fangolitas y limolitas verdes, AV: areniscas varicolores, AR: areniscas rosadas. Las marcas paralelas simbolizan las trazas bioturbadas, las líneas en zig-zag son contactos por fallas y las líneas continuas, contactos transicionales. El resto de la simbología se explica en la figura 2. 
Posteriormente, Bossi y Andreis (1985), al analizar los mismos afloramientos (Tabla 1), modificaron el esquema propuesto por Cuerda y Furque (1981), quedando uno nuevo en el que refieren los miembros inferiores (Areniscas Grises y Fangolitas y Limolitas Verdes) a la Formación Guandacol, los miembros Areniscas Varicolores y Areniscas Rosadas a la Formación Tupe y el resto de la sucesión a la Formación Patquía, aunque en pasaje transicional. Este cambio litoestratigráfico lo fundamentaron a partir correlaciones con otros sectores de la Cuenca Paganzo y por el hallazgo de floras atribuidas a la Biozona NothorhacopterisBotrychiopsis-Gingophyllum (NBG).

Posteriormente, Bercowski y Milana (1990) y Milana y Bercowski (1990) se enfocaron en la Formación Guandacol (miembros Areniscas Grises y Fangolitas y Limolitas Verdes de Cuerda y Furque, 1981), la cual la reinterpretaron como compuesta por depósitos de plataforma marina somera con influencia glaciar.

Una sensible modificación en la estratigrafía de la localidad Río Francia fue propuesta por Gutiérrez et al. (2010). Si bien estos autores continuaron el esquema de Cuerda y Furque (1981) al definir 2 unidades: formaciones Río Francia y Patquía, descartaron por primera vez el Miembro Areniscas Grises como la base de la Formación Río Francia (Tabla 1), por considerarlo una repetición parcial por falla del Miembro Areniscas Varicolores en el sentido de Cuerda y Furque (1981). Además, estos autores documentaron una edad pérmica para el sector superior (=Formación Patquía) en esta localidad, a partir de su contenido palinológico, aunque no agregaron detalles sobre las facies sedimentarias de los niveles superiores.

Por último, Perez Loinaze et al. (2011) confirmaron que la base de la sucesión neopaleozoica correspondía al Miembro Fangolitas y Limolitas Verdes (ex Cuerda y Furque, 1981), el cual sería correlacionable con la Formación Guandacol (Tabla 1). Por lo tanto, la base de la Formación Guandacol, en esta localidad, está apoyada por falla sobre afloramientos de la Formación Tupe y quedó conformada por 5 secciones. Las 2 primeras tendrían influencia glaciar, la tercera y cuarta serían pelitas de ambiente marino offshore y shoreface distal, correlacionables con la transgresión posglacial registrada en la Formación Guandacol en otros sectores de la Cuenca Paganzo (Limarino et al., 2002). Por último, la quinta sección estaría representada por facies de barras costeras intercaladas con pequeños pantanos, en contacto transicional con la suprayacente Formación Tupe.

\section{3. Área de estudio y metodología de trabajo}

Para el estudio estratigráfico y paleoambiental de las formaciones Tupe y Patquía en la quebrada del río Francia, distantes unos $100 \mathrm{~km}$ en línea recta al norte de la ciudad de San Juan, Argentina (Fig. 1), se levantó una columna estratigráfica de detalle de $485 \mathrm{~m}$ de espesor (Fig. 2), en la cual se tomó como base el contacto transicional con la subyacente Formación Guandacol, analizada previamente por Perez Loinaze et al. (2011). Los espesores se midieron con vara de Jacob; los rumbos y buzamientos, con brújula Brunton y se tomaron coordenadas GPS en los cambios de las unidades. Para la asociación de facies fluvial se usó como marco general el esquema formulado por Makaske (2001) y Miall (1996), mientras que para las demás asociaciones se siguió la propuesta de Nichols (2009).

Las impresiones-compresiones de paleoflora fueron limpiadas mecánicamente con cinceles, agujas y martillo neumático que posee el IMCN. El análisis del material megaflorístico se realizó bajo una lupa estereomicroscópica Nikon SMZ800, la que tiene adosada una cámara Nikon DS-Fi1-U2, que se utilizó para tomar las fotografías.

Los ejemplares de megaflora están depositados bajo la sigla PBSJ (Paleobotánica San Juan) en la colección del Instituto y Museo de Ciencias Naturales (IMCN) de la Universidad Nacional de San Juan, Argentina.

\section{Resultados}

\subsection{Estratigrafía y asociación de facies sedimentarias}

La sucesión sedimentaria objeto de estudio (Fig. 2) posee un espesor de $485 \mathrm{~m}$ y fue dividida en base a sus características litológicas en 2 unidades: 1. Formación Tupe, la cual está constituida principalmente por pelitas bioturbadas y areniscas de grano medio a fino, siendo los conglomerados muy escasos. Esta unidad está apoyada sobre la Formación Guandacol de forma transicional. 2. Formación Patquía, constituida por típicos estratos rojos de areniscas con sabulitas y pelitas subordinadas en contacto transicional con la Formación Tupe y 


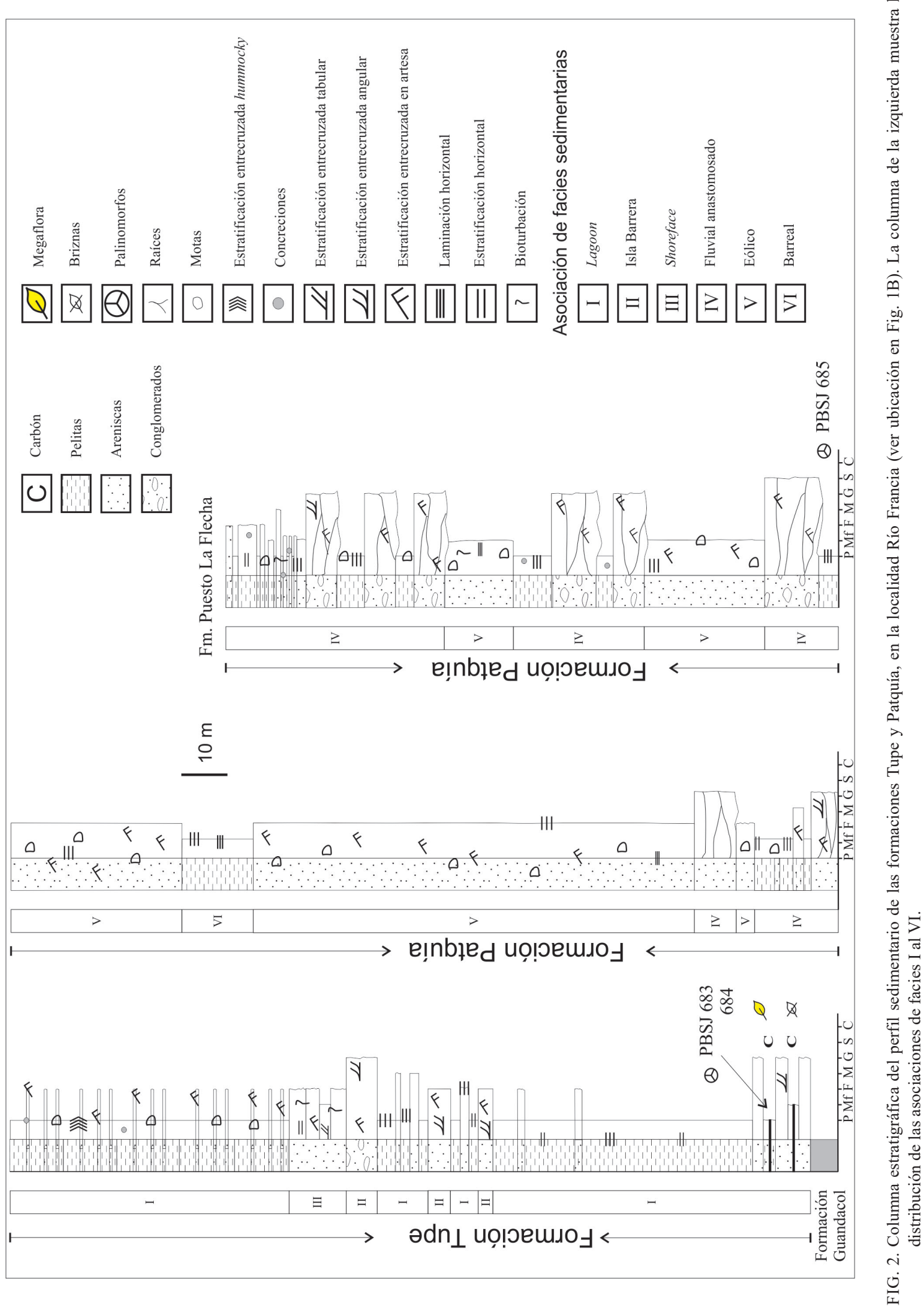


discordante con la sobreyacente Formación Puesto La Flecha.

A continuación se describen sus principales litofacies y su agrupación en asociaciones de facies.

\subsection{Formación Tupe}

\subsubsection{Asociación de facies I (pelitas bioturbadas con tablas de areniscas)}

Descripción: las rocas que constituyen la primera asociación de facies corresponden predominantemente a estratos de pelitas bioturbadas de espesores métricos, que poseen diferentes colores (Fig. 3A), con intercalaciones de estratos tabulares de areniscas de grano grueso a fino de hasta un metro de espesor. De acuerdo con Perez Loinaze et al. (2011) la Formación Tupe se apoya en contacto transicional sobre las rocas de la Formación Guandacol. Esta asociación de facies es 4 veces recurrente en la columna estratigráfica y totaliza un espesor mínimo de $130 \mathrm{~m}$. En los sectores basales de la unidad (areniscas varicolores sensu Cuerda y Furque, 1981) posee intercalaciones de areniscas con pelitas carbonosas y lentes de carbón, que son portadoras tanto de microcomo de megaflora (Fig. 3B). Las areniscas están compuestas por bancos tabulares con laminación y estratificación planar, a veces, con abundantes micas. La composición de estas areniscas es de feldespato potásico y cuarzo, por lo que el primero les confiere una coloración rosada.

Los depósitos finos comprenden principalmente pelitas masivas, laminadas y areniscas muy finas con estratificación horizontal, con estructuras de espina de pez (herring-bone) y láminas de carbón. En estas últimas se colectaron hojas pobremente preservadas de cordaitales y frondes de Euphenopteris sp. (PBSJ 1480) (Fig. 3C) referibles a la Biozona $N B G$. Los depósitos pelíticos en general están bioturbados, presentan grandes motas (de 5 a $10 \mathrm{~cm}$ ), de formas redondas aisladas o botroidales y coloraciones verdosas. Es común la presencia de concreciones centimétricas de composición ferruginosa, en los sectores inferiores de esta asociación de facies, y de areniscas de textura media en las repeticiones posteriores. Las pelitas a veces preservan ondulitas levemente asimétricas (Fig. 3D).

Interpretación: Se interpreta que esta asociación de facies fue generada por 2 diferentes procesos sedimentarios. Por un lado, los depósitos de pelitas mayoritarios en la asociación, con intercalaciones de carbón serían producto de flujos de baja energía, con baja capacidad de transporte y predominio de la decantación. La notoria bioturbación que caracteriza esta asociación puede ser interpretada como el resultado de un ambiente con aporte clástico pobre o discontinuo, lo cual genera condiciones propicias para el desarrollo de vida vegetal (Biozona $N B G$ ). La abundante bioturbación que presenta esta asociación de facies, muy probablemente, indicaría la acción de organismos que habrían descompuesto gran parte de la materia orgánica y destruido el arreglo interno de los sedimentos. Por otro lado, los cuerpos de areniscas tabulares, de morfologías simples pueden interpretarse como parte de sistemas unicanalizados, posiblemente sinuosos, que aportarían sedimentos a los cuerpos estancos descritos anteriormente. Además, las areniscas finas laminadas, muy bioturbadas con estratificación entrecruzada del tipo herringbone, indicarían flujos bidireccionales (Reineck, 1975; Tankard y Hobday, 1977; Datta et al., 1999), probablemente de ambiente de lagoon. Estas litofacies que Cuerda y Furque (1981) interpretaron como de paleoambiente fluvial meandroso con niveles palustres, son a su vez compatibles con sistemas depositacionales de lagoons. La última asociación de facies de la Formación Guandacol interpretada por Perez Loinaze et al. (2011) como barras costeras alternadas con pantanos, sería congruente con la posterior formación de lagoons.

La primera recurrencia de esta asociación de facies es parcialmente correlacionable con el Miembro Areniscas Varicolores sensu Cuerda y Furque (1981). De las muestras palinológicas, extraídas de las pelitas y areniscas muy finas carbonosas de la primera recurrencia de esta facies (PBSJ 683 y 685), Gutiérrez et al. (2010 obtuvieron 2 asociaciones palinológicas que refirieron a la Zona DM (Raistrickia densa-Convolutispora muriornata, Césari y Gutiérrez, 2001), dominadas por esporas triletes (vinculadas a las Pteridophytas y Lycophytas) y escasos granos de polen monosacados (relacionadas con las Gymnospermas). Esta palinoflora representa la vegetación, de requerimiento hidrohigrófilos, compatible con ambientes en los sectores próximos a los lagoons.

\subsubsection{Asociación de facies II (areniscas sabulíticas con estratificación entrecruzadas)}

Descripción: esta asociación de facies se compone mayoritariamente de areniscas de grano medio 

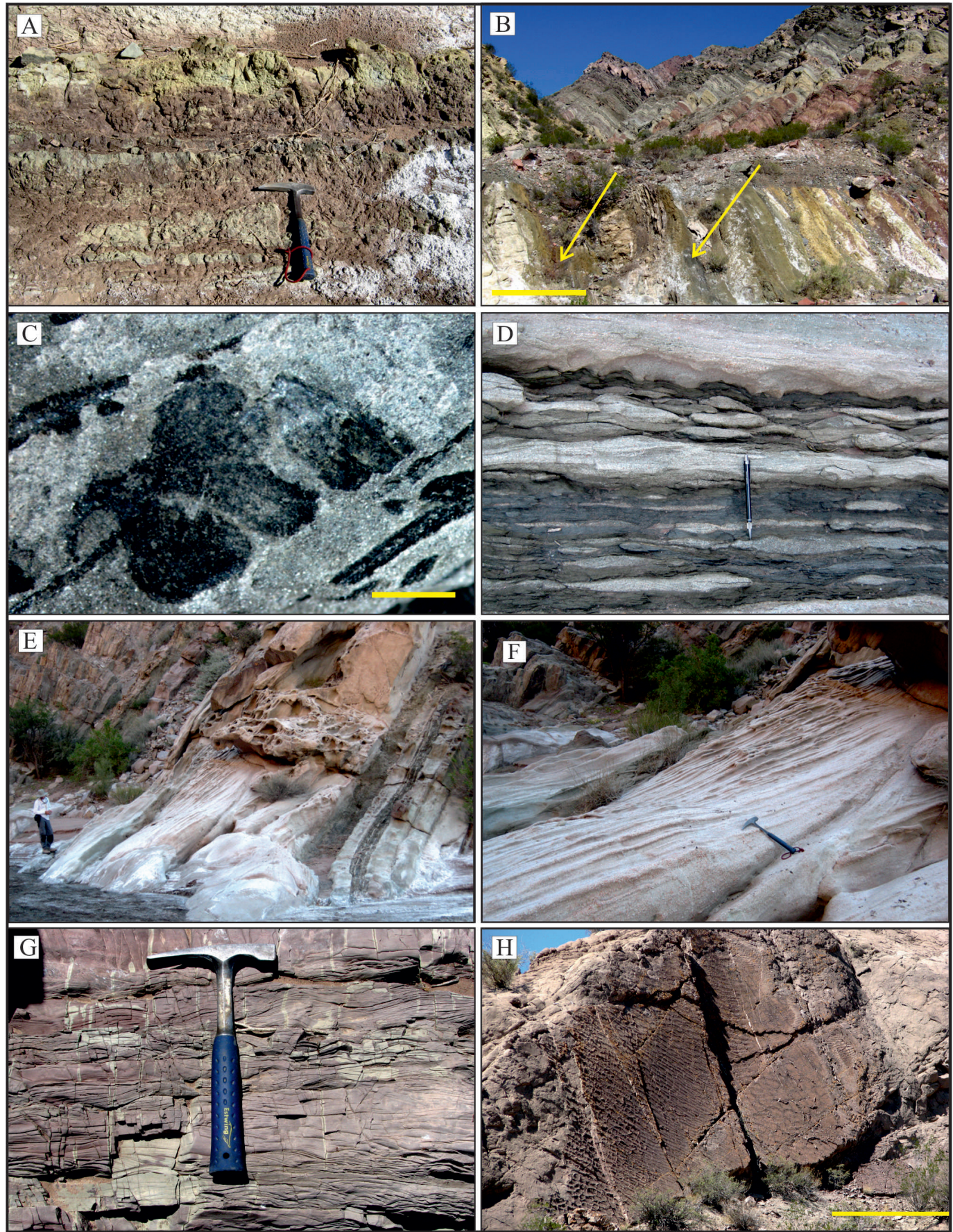

FIG. 3. Detalle de las unidades litológicas y estructuras sedimentarias que constituyen las distintas asociaciones de facies de la Formación Tupe. A-B. Vistas de las pelitas bioturbadas (asociación de facies I), interpretadas como depósitos de lagoons (Miembro areniscas varicolores, sensu Cuerda y Furque, 1981), donde preservan restos megaflorísticos, indicados con flechas. Barra de escala en $\mathrm{B}=1 \mathrm{~m}$. C. Euphenopteris sp. (escala: $1 \mathrm{~cm}$ ). D. Ondulitas simétricas a levemente asimétricas, tipo flaser, presentes en las rocas pelíticas. E-F. Vistas de los sets de areniscas medias a gruesas de forma tabular, típicas de la asociación de facies II. F. Véase la potencia, los contactos entre sets y el entrecruzamiento tabular planar a gran escala (2 m). G. Detalle de ondulitas simétricas en areniscas, con bioturbación vertical. H. Trenes de ondulitas en areniscas, vista en planta, la barra de color amarillo es aproximadamente $1 \mathrm{~m}$ de largo. 
a grueso regularmente seleccionadas, de arreglo granocreciente a gravas finas. Es 3 veces recurrente en la sucesión, por lo general no supera los $5 \mathrm{~m}$ de potencia (Fig. 3E). Las litofacies arenosas tienen como característica principal el tamaño de sus sets (hasta $2 \mathrm{~m}$ de espesor, Fig. 3F) con estratificación entrecruzada tangencial, además de la forma tabular de los estratos. La matriz de las gravas tiene una mala selección y composición similar a los clastos.

Los asomos medios de esta asociación de facies se caracterizan por un incremento notorio del tamaño de los clastos (tamaño areniscas de grano grueso) y por aumentar de forma clara la proporción de feldespato potásico que acompaña los clastos de cuarzo.

Interpretación: la ausencia de litologías de grano fino en estas litofacies, el tamaño de los sets que la componen, la marcada tabularidad de los estratos y principalmente el tamaño de los sets entrecruzados y las formas tabulares de los estratos indican que muy probablemente se habrían depositado en ambientes de islas barreras (Heward, 1981). El entorno que acompaña esta asociación de facies, al intercalarse con lagoons, es interpretado generalmente en rangos micro- a mesomareal, formada bajo condiciones de estabilidad o leve aumento relativo del nivel del mar (Hoyt, 1967; FitzGerald y Buynevich, 2003).

\subsubsection{Asociación de facies III (areniscas con ondulitas)}

Descripción: se caracteriza por la alternancia de pelitas laminadas con areniscas finas gris claro, macizas o con estratificación entrecruzada en artesa, planar asintóticas en la base, y con ondulitas simétricas con formas preservadas (Fig. 3G). Hacia la parte superior de la facies, dominan las areniscas ocres de grano medio con estratificación y laminación planar, entrecruzamientos en artesa, hummockys y ondulitas ascendentes (climbing ripples) (Fig. $3 \mathrm{H})$.

Interpretación: las cambiantes características de formas de las ondulitas indican un cambio en el sentido de los flujos (Dabrio, 1984). Por un lado, las ondulitas simétricas preservadas muestran flujos bidireccionales y sobre estas, los climbing ripples flujos unidireccionales (Dabrio, 1984). Por otro lado, la presencia de apilamientos de hummockys (depósitos de tormenta) evidencia cercanía a la costa (Dabrio, 1984). Perez Loinaze et al. (2011) interpretaron la sección 4 de la Formación Guandacol como un ambiente de shoreface distal, en cambio la Formación Tupe presentaría condiciones más someras que las secciones superiores de la Formación Guandacol, a partir del aumento en la proporción de areniscas $\mathrm{y}$ las estructuras unidireccionales y bidireccionales que presentan, interpretándose como depósito de shoreface proximal.

\subsection{Formación Patquía}

\subsubsection{Asociación de facies IV (estratos de areniscas con pelitas rojas)}

Descripción: esta asociación de facies es 5 veces recurrente en la columna y en la primera recurrencia se apoya sobre los estratos de la Formación Tupe, de forma transicional de acuerdo con Bossi y Andreis (1985). Se alterna principalmente con la asociación de facies $\mathrm{V}$ en lo que previamente se refiriera en parte al Miembro Areniscas Rosadas de Cuerda y Furque (1981) y a la Formación Patquía sensu Bossi y Andreis (1985).

Las características principales son la presencia de bancos de areniscas medias a gruesas y sabulitas, que componen más del 50\% del depósito (Fig. 4A); estos tienen formas lentiformes y poseen bases erosivas. De forma minoritaria, hay bancos de pelitas. Las estructuras sedimentarias más comunes en las psamitas son el entrecruzamiento en artesa y masivas. Es común la presencia de bloques de pelitas rojas entre 0,15 y $0,30 \mathrm{~m}$ de diámetro en la base de los estratos de areniscas gruesas a sabulíticas.

Los depósitos pelíticos son de colores rojizos, tienen de 1 a $1,5 \mathrm{~m}$ de espesor, composiciones arcillosas, motas verdes, superficies de deslizamientos (slickensides), estructuras laminadas o masivas y en pocos sectores hay pelitas carbonosas, con restos vegetales indeterminados. Estos cuerpos preservaron contenido palinológico (PBSJ 684; Gutiérrez et al., 2010). Dentro de estos estratos son comunes los lentes de areniscas medias de $0,5 \mathrm{~m}$ de espesor y varios metros de extensión lateral a veces apilados, además de concreciones de bordes irregulares, con tamaños centimétricos que no superan los $10 \mathrm{~cm}$ de diámetro y de composición de arenisca fina con centro cementado de sílice. En los estratos de pelitas son comunes raíces de 2 a $4 \mathrm{~cm}$ de sección por 15 a $20 \mathrm{~cm}$ de largo, paralelos a la estratificación (Fig. 4B).

Interpretación: entre los principales tipos de acumulación descriptas, se encuentran los depósitos sabulíticos lentiformes de canal (Miall, 1996), donde es común la aparición de indicios de planicies de inundación erosionados (bloques de pelitas en 

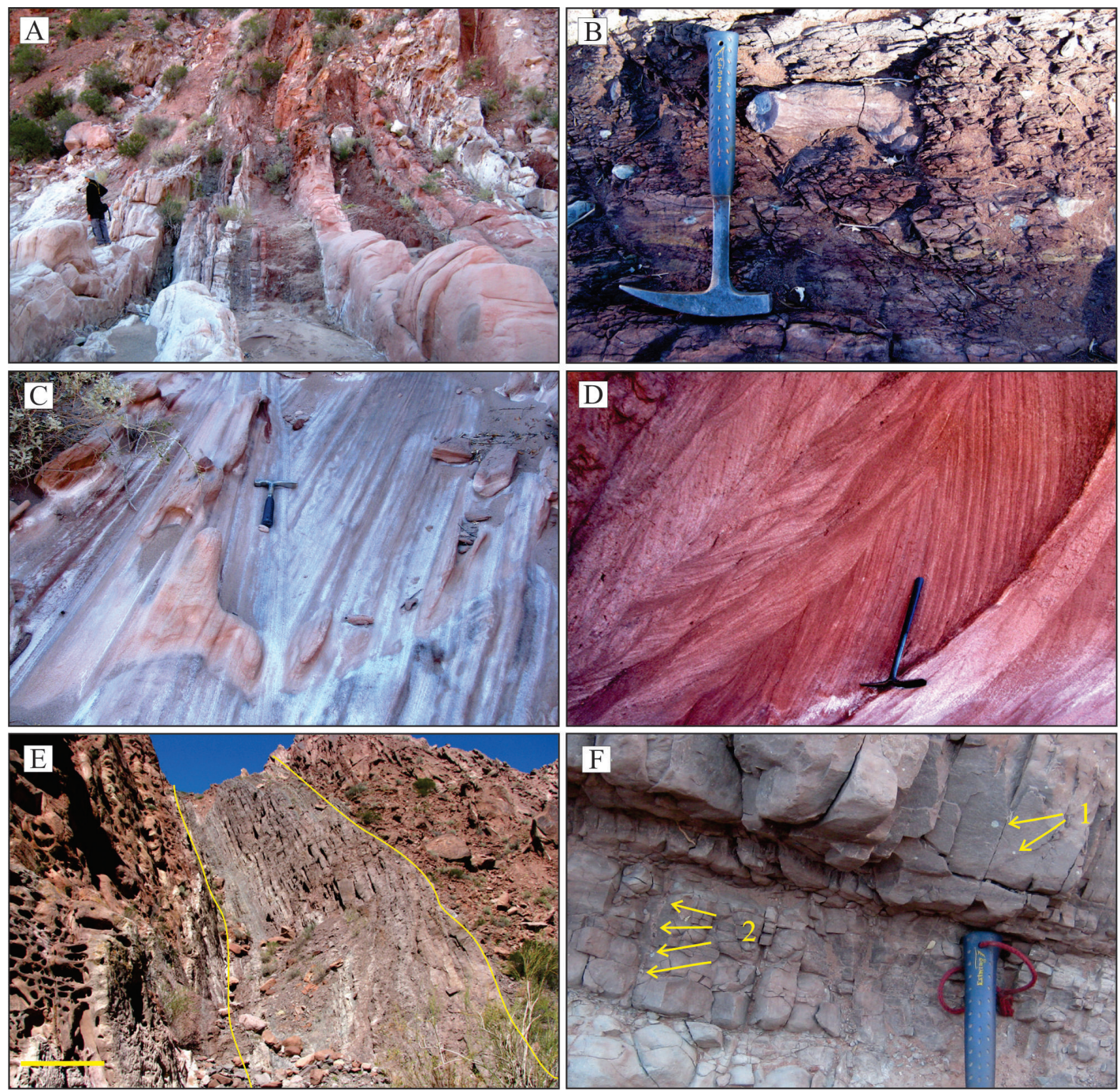

FIG. 4. A. Depósitos lentiformes de areniscas rojas de la Formación Patquía, asociación de facies IV, con preservación de llanuras de inundación. B. Bioturbación de los depósitos de planicies de inundación con presencia de raíces. C-D. Distintos tipos de formas de estratos de areniscas rojas de grano fino acuñados, tabulares con entrecruzamientos tabular planar y en artesa principalmente. E. Vista general de la asociación de facies VI (incluida entre las líneas amarillas), constituida por estratos de areniscas de grano medio a fino con estratificación horizontal, la barra amarilla representa $1 \mathrm{~m}$. F. Detalle de la bioturbación, las flechas marcan halos de raíces en posición transversal (1) y en una sección vertical (2).

la base de los estratos psamíticos). Además, hay desarrollo de planicies de inundación con evidencias de exposición subaérea prolongada como lo indica la presencia de restos de raíces, motas, superficies de deslizamientos, concreciones y briznas vegetales. De acuerdo con el criterio de Retallack (1988) y la clasificación de los suelos del Soil Survey Staff (1999), estos paleosuelos podrían corresponder al tipo vertisoles, característicos de climas estacionales.
Por lo tanto, esta facies se interpreta como depositada bajo un sistema fluvial multicanalizado, con canales con poca movilidad, posiblemente, podría corresponder a un sistema fluvial anastomosado (Makaske, 2001), aunque las distintas formas de acumulación en las 5 recurrencias puede deberse a un mismo sistema fluvial con diferentes características del espacio de acomodación disponible en cada caso. 
De los sectores superiores (PBSJ 684) de esta facies (Fig. 2), Gutiérrez et al. (2010) obtuvieron una asociación palinológica dominada por granos de polen bisacados, monosacados y estriados (vinculados principalmente a las Gymnospermas, y algunas Pteridospermas-Glossopteridales), con esporas trilete (relacionadas con la Pteridophytas). Esta palinoflora refleja la vegetación, mayoritariamente con requerimientos xerófilos, que se habría desarrollado en los sectores altos de la zona de depositación; también muestra un empobrecimiento de la vegetación autóctona (Pteridophytas, Sphenofitas, Lycophytas), probablemente exprese el inicio de la aridización del clima imperante durante la depositación.

\subsubsection{Asociación de facies V (areniscas finas bien seleccionadas)}

Descripción: esta facies es la de mayor potencia de la unidad, con un espesor total de $177 \mathrm{~m}$ de areniscas rojas, en 5 recurrencias. Se caracteriza por la presencia de areniscas finas a muy finas con muy buena selección, alta porosidad y sin matriz. Los sets tienen formas acuñadas de hasta $1 \mathrm{~m}$ de espesor o bien tabulares de espesores de hasta 0,40 m (Fig. 4C). Las estructuras sedimentarias más comunes son estratificación entrecruzada en artesa, laminación ondulítica, tabular planar, planar tangencial y horizontal (Fig. 4D). Además, poseen altos porcentajes de granos de cuarzo y de forma complementaria de feldespato potásico. Como rasgo de campo complementario es notable la cantidad de concreciones circulares-subesféricas de hasta $0,30 \mathrm{~m}$ de diámetro y geoformas de nidos de avispas.

Interpretación: a partir de la homogeneidad del tamaño de grano fino de las areniscas, como así también de las formas acuñadas de los sets y su limitado espesor, se puede inferir que fueron depositados por procesos eólicos a escala pequeña y mediana (micro- y mesoformas), compatibles con zibars, gozes, protodunas y dunas (Tripaldi y Limarino, 2008). Entre sus características más destacables está las laminaciones entrecruzada tabular planar, ondulítica y horizontal que pueden interpretarse como migración de óndulas de arena sobre geoformas de pequeño porte (Tripaldi y Limarino, 2008).

\subsubsection{Asociación de facies VI (areniscas con estratificación tabular)}

Descripción: esta asociación de facies está expuesta una vez en el tercio superior de la Formación
Patquía y tiene $13 \mathrm{~m}$ de potencia. Está representada de forma monótona por areniscas de grano fino a medio, macizas o con estratificación y laminación horizontal (Fig. 4E). Los estratos de areniscas son tabulares con bases planas y generalmente macizos. Es común la presencia de pequeños halos de raíces perpendiculares en forma circular o paralelos en forma tubular (Fig. 4F).

Interpretación: esta asociación de facies puede interpretarse como depositada en zonas deprimidas, donde drenan los sistemas fluviales; generalmente solo recibirá sedimento de grano muy fino después de grandes inundaciones, y los canales de distribución se extenderán a esta zona solo durante eventos de inundación extrema (Kelly y Olsen, 1993) alimentando así a lagos efímeros de barreal o playa lake, en sus sectores marginales (sand flat). Alternativamente, la zona de cuenca puede caracterizarse por ambientes eólicos (Langford, 1989). La marcada tabularidad de los bancos y la base de los estratos indicarían poca energía de los flujos. Los pequeños, aunque abundantes, halos de raíces en las psamitas masivas y estratificadas, serían indicadores de amplios momentos de no depositación en los cuales se pudieron desarrollar suelos incipientes. La alternancia de los paleoambientes eólico, barreal y fluvial efímero están registrados en la Formación Patquía (Limarino et al., 1986). Según Mountney (2006), estos sistemas pueden desarrollarse bajo condiciones climáticas desérticas y comúnmente alternándose con dunas eólicas. En las capas rojas pérmicas de la Formación De La Cuesta, Spalletti et al. (2010) identificaron alternancia de ambientes desérticos como eólicos y fluviales efímeros con playa lake, lo cual amplía la interacción de estos ambientes en la Cuenca Paganzo.

\section{Edad}

Los primeros hallazgos fósiles de plantas en las rocas de la Formación Tupe corresponden a impresiones-compresiones de Calamites peruvianus Gothan 1928 encontrados por Cuerda y Furque (1981). Posteriormente, Bossi y Andreis (1985) detectaron la presencia de Paracalamites sp., Botrychiopsis weissiana (Kurtz) Archangelsky y Arrondo 1971, Nothorhacopteris argentinica Archangelsky 1983, licofitas pequeñas y semillas atribuibles a la Biozona $N B G$. Estos hallazgos se realizaron, probablemente, en los mismos niveles estratigráficos donde Cuerda y Furque (1981) hallaron los primeros restos de plantas 
fósiles (Tabla 1). En el presente trabajo se suman algunas hojas fragmentarias de cordaitales y frondes de Euphenopteris sp. (Fig. 3C), los cuales también se consideran colectados en los mismos niveles que los anteriores, correspondientes a la Formación Tupe. Si bien la Biozona $N B G$ posee un rango temporal amplio, teniendo en cuenta el esquema litoestratigráfico propuesto por Gulbranson et al. (2010), en la sección de Huaco, los carbones portadores de la Flora $N B G$ arrojaron una edad radimétrica de $315,46 \pm 0,072 \mathrm{Ma}$ que podría correlacionarse con los carbones en la localidad Río Francia. Además, en estos niveles, Gutiérrez et al. (2010) caracterizaron una microflora (PBSJ 683 y 684) entre las que destacan Raistrickia densa Menéndez, 1965, Convolutispora muriornata Menéndez, 1965, Anapiculatisporites concinnus Playford, 1962, Apiculatisporites variornatus di Pasquo, Azcuy y Souza, 2003, Apiculatasporites parviapiculatus Azcuy, 1975, Apiculiretusispora alonsoi Ottone 1989, Brevitriletes parmatus (Balme y Hennelly) Backhouse 1991, Cristatisporites stellatus (Azcuy) Gutiérrez y Limarino 2001, Verrucosisporites quassigobetti Jones y Truswell 1992 y Foveosporites hortonensis (Playford) Azcuy 1975.

Las microfloras de la Formación Guandacol fueron referidas por Perez Loinaze et al. (2011) a la Subbiozona A de la Biozona Raistrickia densaConvolutispora muriornata (DM). La Subbiozona A representaría el intervalo Serpukhoviano tardíoBashkiriano medio (Limarino et al., 2014; Gutiérrez et al., 2018). Mientras que las microfloras de la Formación Tupe son aquí referidas a la Subbiozona B de la Biozona $D M$, que representaría el intervalo Bashkiriano tardío-Gzheliano medio (Limarino et al., 2014; Gutiérrez et al., 2018).

Por su parte, la Formación Patquía brindó un solo nivel fosilífero de palinomorfos (PBSJ 685), en el cual Gutiérrez et al. (2010) documentaron la presencia de Barakarites rotatus (Balme y Hennelly) Bharadwaj y Tiwari 1964, Caheniasaccites flavatus Bose y Kar, 1966, Hamiapollenites fusiformis MarquesToigo emend. Archangelsky y Gamerro, 1979, Polarisaccites bilateralis Ybert y Marques-Toigo, 1971, Protohaploxypinus limpidus (Balme y Hennelly) Balme y Playford, 1967, Scheuringipollenites barakarensis (Tiwari) Tiwari, 1973, S. medius (Burjack) Dias-Fabrício, 1981, S. ovatus (Balme y Hennelly) Foster, 1975, Striatopodocarpites cancellatus (Balme y Hennelly) Hart, 1963, Vittatina costabilis Wilson emend. Tschudy y Kosanke, 1966,
V. minima Jansonius, 1962, V. subsaccata Samoilovich emend. Jansonius, 1962.

Originalmente, Gutiérrez et al. (2010) refirieron esta asociación a la Biozona Lueckisporites-Weylandites ( $L W$, Césari y Gutiérrez, 2001), sin embargo, recientemente Gutiérrez et al. (2018) plantearon que probablemente esta microflora debería ser reubicada en la Biozona Pakhapites fusus-Vittatina subsaccata (FS, Césari y Gutiérrez, 2001) antes que en la Biozona $L W$, a partir del análisis estadístico que realizaron de las microfloras de edades pérmicas del oeste de Argentina.

La Biozona FS incluiría el lapso que va desde fines del Pensilvaniano hasta el Cisuraliano tardío (Gutiérrez et al., 2018).

\section{Discusión}

La estratigrafía en la localidad Río Francia comienza con un claro pasaje de paleoambientes influenciados por la glaciación del Sepurkhoviano tardío-Bashkiriano temprano, registrado en las primeras facies de la Formación Guandacol, las cuales son seguidas por un evento de transgresión marina y una posterior somerización del sistema, que terminan en facies de shoreface en el techo de la Formación Guandacol (Perez Loinaze et al., 2011).

Las 3 asociaciones de facies que caracterizan a la Formación Tupe están compuestas por paleoambientes transicionales relacionados con una zona costera, donde estos sistemas depositacionales fluctuarían muy probablemente de forma autocíclica. Según Hayes (1975), las costas dominadas por olas son las que pueden construir islas barreras, lagoons, en régimen micromareal. De esta forma, los sistemas de lagoons, islas barreras y shoreface son transicionales a la Formación Guandacol, como así también lo son el límite entre las formaciones Tupe y Patquía (Bossi y Andreis, 1985). Las asociaciones de facies de la Formación Tupe en esta localidad muestran una sucesión estable con pequeñas fluctuaciones del nivel del mar alternándose por aproximadamente $70 \mathrm{~m}$ (Fig. 2). Si bien los últimos metros de la Formación Tupe se caracterizan por coloraciones rojo pálido a rosado (Miembro Areniscas Rosadas de Cuerda y Furque, 1981), es en la Formación Patquía donde se observa en forma definida la coloración rojo oscuro o ladrillo de las sedimentitas.

La Formación Patquía incluye asociaciones de facies netamente continentales (IV, V y VI), 
correspondientes a sistemas fluvial anastomosado, eólico y barreal, respectivamente, conformando una definitiva continentalización en este sector. Estas asociaciones de facies tienen una singular importancia regional dentro de la cuenca, debido a que son equivalentes al evento árido ampliamente reconocido para el Pérmico (Limarino et al., 1996), más precisamente para el Cisuraliano (Biozona $F S$, Gutiérrez et al., 2018). La coloración rojiza que poseen estos afloramientos es un rasgo característico también en el tope de las sucesiones neopaleozoicas más australes de la Cuenca Paganzo (e.g., formaciones Andapaico y La Deheza), aunque no necesariamente de ambientes eólicos (Correa y Gutiérrez, 2014).

De esta forma, la localidad Río Francia se vincula como un punto estratégico de correlación en la Cuenca Paganzo. Al norte, en la localidad de Huaco, la Formación Tupe presenta paleoambientes sedimentarios costeros y asociados a la costa (Desjardins et al., 2009), los cuales serían temporalmente correlacionables con la sucesión descrita en la localidad Río Francia (asociaciones de facies I, II y III). En cambio, al sur en la Formación La Deheza, en sus sectores medios, se destacan paleoambientes sedimentarios de ingresión marina y fluviales meandrosos con preservación de carbones, los cuales serían correlacionables con la Formación Tupe en Río Francia (Fig. 5A).
Por otro lado, la Formación Patquía en la localidad de Huaco muestra una clara continentalización con paleoambientes sedimentarios áridos como eólico y fluvial efímero (Milana, 1993; Perez Loinaze et al., 2014), correlacionables con las asociaciones de facies IV, V y VI descritas en el presente trabajo.

Al sur de la localidad Río Francia, los sectores superiores de la Formación La Deheza (Correa y Gutiérrez, 2014) y la Formación Andapaico (Correa et al., 2012) están compuestos por capas rojas de paleoambientes sedimentarios de isla barrera, eólico y lagoon. Estos sectores son temporalmente correlacionables con la Formación Patquía en Río Francia (Gutiérrez et al., 2018), por lo que determinaría una paleogeografía cambiante para estos momentos de la Cuenca Paganzo y posibles evidencias de líneas costeras continuas, las cuales de norte a sur van continentalizándose hacia el Pérmico inferior (Cisuraliano) (Fig. 5B).

\section{Conclusiones}

El estudio realizado en la localidad Río Francia ha permitido obtener las siguientes conclusiones:

- La estratigrafía en la localidad Río Francia quedaría establecida para la Formación Guandacol en contacto por falla sobre una repetición parcial de

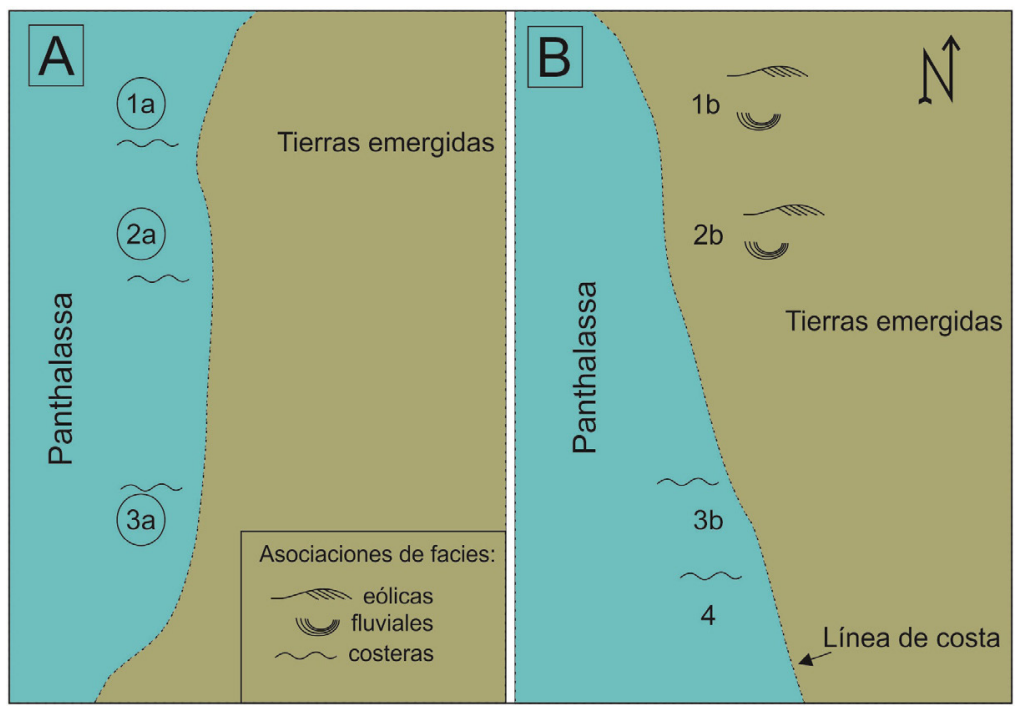

FIG. 5. Esquema fuera de escala de la paleogeografía del borde occidental de la Cuenca Paganzo a la latitud de la actual precordillera Central. Los círculos corresponden a las localidades correlacionadas: 1: Huaco (1a: Formación Tupe; 1b: Formación Patquía); 2: Río Francia (2a: Formación Tupe; 2b: Formación Patquía); 3: Maradona (3a: sector medio superior de la Formación La Deheza; 3b: sector superior); 4: Bachongo (4: Formación Andapaico). 
la Formación Tupe (Gutiérrez et al., 2010; Perez Loinaze et al., 2011). De forma transicional se suceden los depósitos de las formaciones Tupe y Patquía, esta última es cubierta en discordancia con la Formación Puesto La Flecha.

- Se diferenciaron 3 asociaciones de facies para la Formación Tupe, todas de paleoambientes transicionales o relacionadas con la línea de costa. I, lagoon; II, isla barrera y III, shoreface. Además, en la base de la unidad, se encontraron restos fósiles de cordaitales y frondes de Euphenopteris sp. (PBSJ 1480) (Fig. 3C) referibles a la Biozona Nothorhacopteris-Botrychiopsis-Gingophyllum, los cuales se consideran que son de los mismos niveles donde Cuerda y Furque (1981) y Bossi y Andreis (1985) dieron a conocer los primeros descubrimientos.

- Se determinaron las siguientes 3 asociaciones de facies para la Formación Patquía: IV, fluvial anastomosado; V, eólico y VI, sistema lacustre de barreal. Toda la unidad se caracteriza por sus coloraciones rojo ladrillo y por representar completamente ambientes continentales.

- La edad de toda la secuencia neopaleozoica aflorante en la localidad Río Francia, a partir de la información palinológica, estaría acotada para el final del Carbonífero Temprano (Sepurkhoviano tardío), como edad inferior de la Biozona DM, Subbiozona A de la Formación Guandacol en la base. La edad de la parte superior de la sucesión sería pérmica temprana (Cisuraliano tardío), en los sectores superiores de la Formación Patquía.

- A partir de los datos de edad y las comparaciones con las localidades de la precordillera Central al norte (Huaco) y al sur (Maradona y Bachongo), se estableció una correlación en la cual se interpreta que a partir del Sepurkhoviano tardío en adelante, este sector de la Cuenca Paganzo mostraría una zona costera continua. Esta situación para la Formación Patquía y sus equivalentes, cambiaría hacia el Pérmico Inferior (Cisuraliano) donde se produciría una continentalización de norte a sur (Fig. 5).

\section{Agradecimientos}

Se desea expresar el agradecimiento a los Dres. O. Limarino, L. Balarino, B. Cariglino, L. Carrevedo, P. Santi Malnis y M. Rothis, por su valiosa ayuda en el campo. A la Agencia Nacional de Promoción Científica y Tecnológica y al Consejo Nacional de Investigaciones
Científica y Técnicas, por el financiamiento de los trabajos de campo, mediante los proyectos ANPCYTPICT 32693, PRÉSTAMO BID-PICT 2010-2196 y CONICET-PIP 0705. Además, los autores desean expresar su agradecimiento a los Dres. F. Colombo Piñol, y W. Vivallo por sus valiosos aportes que mejoraron sustancialmente este trabajo.

\section{Referencias}

Amos, A.J.; Rolleri, E. 1965. El Carbónico marino en el valle Calingasta-Uspallata, San Juan-Mendoza. Boletín de Informaciones Petroleras: 368 p. Buenos Aires.

Archangelsky, S. 1983. Nothorhacopteris, a new generic name for some Carboniferous monopinnate fronds of Gondwanaland (=Rhacopteris ovata auct. and Pseudorhacopteris Rigby, 1973). Review of Palaeobotany and Palynology 38: 157-172.

Archangelsky, S. 1987. El Sistema Carbonífero en la República Argentina. Academia Nacional de Ciencias: 383 p. Córdoba.

Archangelsky, S. 1996. El Sistema Pérmico en la República Argentina y en la República Oriental del Uruguay. Academia Nacional de Ciencias: 417 p. Córdoba.

Archangelsky, S.; Arrondo, O.G. 1971. Paleophytologia Kurtziana III. 2. Estudio sobre el género Botrychiopsis Kurtz (=Gondwanidium Gothan) del Carbónico y Pérmico gondwánico. Ameghiniana 8: 189-227.

Archangelsky, S.; Gamerro, J.C. 1979. Palinología del Paleozoico Superior en el subsuelo de la Cuenca Chacoparanense. Argentina. I-estudio sistemático de los palinomorfos de 3 perforaciones de la provincia de Córdoba. Revista Española de Micropaleontología 11 (3): 417-478.

Azcuy, C.L. 1975. Miosporas del Namuriano y Westfaliano de la comarca Malanzán-Loma Larga, provincia de La Rioja, Argentina. I. Localización geográfica y geológica de la comarca y descripciones sistemáticas. Ameghiniana 12: 1-69.

Backhouse, J. 1991. Permian palynostratigraphy of the Collie Basin, Western Australia. Review of Palaeobotany and Palynology 67: 237-314.

Balme, B.E.; Playford, G. 1967. Late Permian plant microfossils from the Prince Charles Mountains, Antarctica. Revue de Micropaléntologie 10: 179-192.

Bercowski, F.; Milana, J.P. 1990. Sedimentación glacimarina: nueva interpretación para la Formación Guandacol (Carbonífero) en el perfil de Río Francia, Precordillera Central, San Juan. In Reunión Argentina de Sedimentología, No. 3, Actas: 37-42. San Juan. 
Bharadwaj, D.C.; Tiwari, R.S. 1964. On two monosaccate genera from Barakar Stage, India. The Palaeobotanist 12: 139-146.

Bodenbender, G. 1911. Constitución geológica de la parte meridional de la provincia de La Rioja y regiones limítrofes, Córdoba, República Argentina. Boletín de la Academia Nacional de Ciencias 19 (1): 2-211.

Borrello, A.V. 1956. Recursos minerales de la República Argentina. III. Combustibles sólidos minerales. Instituto Nacional de Investigaciones de Ciencias Naturales, Museo B. Rivadavia, Revista Ciencias Geológicas 5: 655 p. Buenos Aires.

Bose, M.N.; Kar, R.K. 1966. Palaeozoic Sporae Dispersae from Congo. I-Kindu-Kalima and Walikale Regions. Annales de Musee Royal de l'Afrique Centrale, Serie in 8, Sciences Geologiques 53: 1-169.

Bossi, G.; Andreis, R. 1985. Secuencias deltaicas y lacustres del Carbónico del centro-oeste argentino. In International Congress Carboniferous Stratigraphy, No.10, Comptes Rendus 3: 285-309. Madrid.

Césari, S.N.; Gutiérrez, P.R. 2001. Palynostratigraphic study of the Upper Paleozoic central-western Argentine sequences. Palynology 24 (1): 113-146.

Césari, S.N.; Limarino, C.O.; Gulbranson, E.L. 2011. An Upper Paleozoic biochronostratigraphic scheme for the western margin of Gondwana. Earth Science Review 106: 149-160.

Correa, G.; Gutiérrez, P.R. 2014. Caracterización estratigráfica, paleoambiental y biocronológica de la Formación La Deheza (Carbonífero Superior-Pérmico Inferior), San Juan, Argentina. Revista Mexicana de Ciencias Geológicas 31 (3): 340-353.

Correa, G.A.; Carrevedo, M.L.; Gutiérrez, P.R. 2012. Paleoambiente y paleontología de la Formación Andapaico (Paleozoico superior, Precordillera Central, Argentina). Andean Geology 39 (1): 22-52. doi: 10.5027/andgeoV39N1-a02.

Cuerda, A.J.; Furque, G. 1981. Depósitos carbónicos de la Precordillera de San Juan, Parte I. Comarca del cerro La Chilca (Río Francia). Revista de la Asociación Geológica Argentina 36 (2): 187-196.

Dabrio González, C.J. 1984. Estructuras sedimentarias primarias. Instituto Geológico y Minero de España. In Ciclo de Seminarios de Sedimentología, No. 1: 13-26.

Datta, B.; Sarkar, S.; Chaudhuri, A.K. 1999. Swaley crossstratification in medium to coarse sandstone produced by oscillatory and combined flows: examples from the Proterozoic Kansapathar Formation, Chhattisgarh Basin, MP, India. Sedimentary Geology 129 (1-2): 51-70.
Desjardins, P.R.; Buatois, L.A.; Limarino, C.O.; Cisterna, G.A. 2009. Latest Carboniferous-earliest Permian transgressive deposits in the Paganzo Basin of western Argentina: Lithofacies and sequence stratigraphy of a coastal-plain to bay succession. Journal of South American Earth Sciences 28 (1): 40-53.

Di Pasquo, M.; Azcuy, C.L.; Souza, P.A. 2003. Palinología del Carbonífero Superior del Subgrupo Itararé en Itaparonga, Cuenca Paraná, estado de Sâo Paulo, Brasil. Parte 1: sistemática de esporas y paleomicrofitoplancton. Ameghiniana 40: 277-296.

Dias-Fabricio, M.E. 1981. Palinologia da Formaçâo Rio Bonito na área de Gravataí-Morungava, Rio Grande do Sul. Pesquisas 14: 69-130.

Fernández Seveso, F.; Pérez, M.; Brisson, I.; Álvarez, L. 1993. Análisis de Cuenca: Técnicas aplicadas a la serie carbónico-pérmica de Paganzo. Boletín de Informaciones Petroleras 33: 77-107.

FitzGerald, D.M.; Buynevich, I.V. 2003. Barrier Islands. In Encyclopedia of Sediments and Sedimentary Rocks (Middleton, G.V.; editor). Kluwer Academic Publishers: 43-48. Dordrecht.

Foster, C. 1975. Permian plant microfossils from the Blair Athol Coal Mesures, Central Queensland, Australia. Palaeontographica Abteilung B 154: 121-171.

González Bonorino, G. 1991. Evolución comparada del margen atlántico de Norteamérica y de la Precordillera de Cuyo. Revista de la Asociación Geológica Argentina 46 (1): 10-19.

Gothan, W. 1928. Bemerkungen zur Alt-Carbonflora von Peru, besonders von Paracas. Neues Jahrbuch für Mineralogie, Geologie und Paläontologie, (Beilagen Band) B59: 292-299. Stuttgart.

Gulbranson, E.L.; Montañez, I.P.; Schmitz, M.D.; Limarino, C.O.; Isbell, J.L.; Marenssi, S.A.; Crowley, J.L. 2010. High-precision $\mathrm{U}-\mathrm{Pb}$ calibration of Carboniferous glaciation and climate history, Paganzo Group, NW Argentina. Geological Society of America Bulletin 122: 1480-1498.

Gulbranson, E.L.; Montañez, I.P.; Tabor, N.J.; Limarino, C.O. 2015. Late Pennsylvanian aridification on the southewestern margin of Gondwana (Paganzo Basin, NW Argentina): A regional expression of global climate perturbation. Palaeogeography, Palaeoclimatology, Palaeoecology 417 (1): 220-235.

Gutiérrez, P.R.; Limarino, C.O. 2001. Palinología de la Formación Malanzán (Carbonífero Superior), La Rioja, Argentina: nuevos datos y consideraciones paleoambientales. Ameghiniana 38: 99-118. 
Gutiérrez, P.R.; Correa, G.A.; Carrevedo, M.L. 2010. Primer registro de palinomorfos de edad pérmica en la Formación Río Francia (Paleozoico Superior, San Juan, Argentina). Revista Museo Argentino de Ciencias Naturales, Nueva Serie 12: 203-216.

Gutiérrez, P.R.; Zavattieri, A.M.; Noetinger, S. 2018. The Lopingian palynological Guttulapollenites hannonicusCladaitina veteadensis assemblage zone of Argentina, stratigraphical implications for Gondwana. Journal of South American Earth Sciences 88: 673-692. doi: 10.1016/j.jsames.2018.09.004.

Hart, G.F. 1963. Microflora investigation of the Lower Coal Measures (K2); Ketewaka-Mchuchuma Coalfield. Bulletin Geological Survey Tanganyika 30: 1-60.

Hayes, M.O. 1975. Morphology of sand accumulation in estuaries: an introduction to the symposium. In Estuarine Research, Volume II: Geology and Engineering (Cronin, L.E.; editor). Academic Press: 3-22. New York.

Henry, L.C.; Isbell, J.L.; Limarino, C.O.; McHenry, L.J.; Fraiser, M.L. 2010. Mid-Carboniferous deglaciation of the Protoprecordillera, Argentina recorded in the Agua de Jagüel palaeovalley. Palaeogeography, Palaeoclimatology, Palaeoecology 298 (1-2): 112-129.

Heward, A.P. 1981. A review of wave-dominated clastic shoreline deposits. Earth-Science Reviews 17 (3): 223-276.

Hoyt, J.H. 1967. Barrier Island Formation. Geological Society of America, Bulletin 78: 1123-1136.

Jansonius, J. 1962. Palynology of Permian and Triassic sediments, Peace River area, western Canada. Palaeontographica Abteilung B110: 35-98.

Jones, M.J.; Truswell, E.M. 1992. Late Carboniferous and Early Permian palynostratigraphy of the Joe Group, southern Galilee Basin, Queensland, and implications for Gondwanan stratigraphy. Bureau of Mineral Resources, Journal of Australian Geology and Geophysics 13: 143-185.

Kelly, S.B.; Olsen, H. 1993. Terminal fans-a review with reference to Devonian examples. Sedimentary Geology 85 (1-4): 339-374.

Langford, R.P. 1989. Fluvial-aeolian interactions: Part 1. Modern systems. Sedimentology 36: 1023-1035.

Limarino, C.O.; Gutiérrez, P.R. 1990. Diamictites in the Agua Colorada Formation. New evidence of Carboniferous glaciations in South America. Journal of South American Earth Sciences 3 (1): 9-20.

Limarino, C.O.; Sessarego, H.; Césari, S.; López Gamundí, O. 1986. El perfil de la Cuesta de Huaco, estratotipo de referencia (hipoestratotipo) del Grupo Paganzo en la Precordillera Central. Anales de la Academia Nacional de Ciencias Exactas, Físicas y Naturales 38: 81-109.
Limarino, C.; Gutiérrez, P.R.; López-Gamundí, O.R.; Fauqué, L.; Lech, R.R. 1996. Cuencas Río Blanco y Calingasta-Uspallata. In El Sistema Pérmico en la República Argentina y en la República Oriental del Uruguay (Archangelsky, S.; editor). Academia Nacional de Ciencias: 141-154. Córdoba.

Limarino, C.O.; Césari, S.N.; Net, L.I.; Marenssi, S.A.; Gutiérrez, P.R., Tripaldi, A. 2002. The Upper Carboniferous postglacial transgression in the Paganzo and Río Blanco basins (northwestern Argentina): facies and stratigraphic significance. Journal of South American Earth Sciences 15 (4): 445-460.

Limarino, C.O.; Césari, S.N.; Spalletti, L.A.; Taboada, A.C.; Isbell, J.L.; Geuna, S.; Gulbranson, E.L. 2014. A paleoclimatic review of southern South America during the late Paleozoic: A record from icehouse to extreme greenhouse conditions. Gondwana Research 25: 1396-1421. doi: 10.1016/j.gr.2012.12.022.

Llambías, E.J. 1999. El magmatismo gondwánico durante el Paleozoico Superior-Triásico. In Geología Regional Argentina (Caminos, R.; editor). Servicio Geológico Minero Argentino, Anales 29: 349-363. Buenos Aires.

López Gamundí, O.R.; Martínez, M. 2000. Evidence of glacial abrasion in the Calingasta-Uspallata and western Paganzo basins, mid- Carboniferous of western Argentina. Palaeogeography, Palaeoclimatology and Palaeoecology 159: 145-165.

Makaske, B. 2001. Anastomosing rivers: a review of their classification, origin and sedimentary products. EarthScience Reviews 53 (3-4): 149-196.

Marenssi, S.A.; Tripaldi, A.; Limarino, C.O.; Caselli, A.T. 2005. Facies and architecture of a Carboniferous grounding-line system from the Guandacol Formation, Paganzo Basin, northwestern Argentina. Gondwana Research 8 (2): 187-202.

Menéndez, C.A. 1965. Contenido palinológico en sedimentos con "Rhacopteris ovata" (Mc Coy) Walk, de la sierra de Famatina, La Rioja. Revista del Museo Argentino de Ciencias Naturales B. Rivadavia e Instituto Nacional de Investigación de las Ciencias Naturales, Paleontología 1: 45-80.

Miall, A. 1996. The Geology of Fluvial Deposits. Sedimentary Facies Basin Analysis and Petroleum Geology. Springer-Verlag: 582 p. New York.

Milana, J.P. 1993. Estratigrafía de eolianitas en la zona de Jáchal-Huaco, Precordillera de San Juan. Revista de la Asociación Geológica Argentina 48 (3-4): 283-298.

Milana, J.P.; Bercowski, F. 1990. Facies y geometría de depósitos glaciales en un paleovalle Carbonífero de Precordillera Central, San Juan, Argentina. In Reunión 
Argentina de Sedimentología, No. 3, Actas 3: 199-204. San Juan.

Mountney, N.P. 2006. Eolian facies models. In Facies models revisited (Walker, R.G.; Posamentier, H.; editores). SEPM (Society for Sedimentary Geology), Special Publication 84: 19-83.

Net, L.I.; Limarino, C.O. 2006. Applying sandstone petrofacies to unravel the Upper Carboniferous evolution of the Paganzo Basin, northwest Argentina. Journal of South American Earth Sciences 22: 239-254.

Nichols, G. 2009. Sedimentology and stratigraphy. John Wiley and Sons: 419 p. United Kingdom.

Ottone, E.G. 1989. Palynoflores de la Formation Santa Máxima, Paléozoique supérieur, République Argentine. Palaeontographica Abteilung B, 213: 89-187.

Perez Loinaze, V.S.; Limarino, C.O.; Césari, S.N. 2011. Palynological study of the Carboniferous sequence at Río Francia Creek, Paganzo Basin, Argentina. Ameghiniana 48: 589-604.

Perez Loinaze, V.S.; Limarino, C.O.; Césari, S.N. 2014. Carboniferous outcrops at La Herradura creek, San Juan Province (western Argentina), revisited: age of the transgressions. Andean Geology 41 (1): 83-105. doi: 10.5027/andgeoV41n1-a04.

Playford, G. 1962. Lower Carboniferous microfloras of Spitsebergen. Part 1. Palaeontology 5: 550-618.

Reineck, H.-E. 1975. German North Sea tidal flats. In Tidal Deposits (Ginsburg, R.N.; editor). Springer: 5-12. New York.

Retallack, G.J. 1988. Field recognition of paleosols. In Paleosols and Weathering Through Geologic Time: Principles and Applications (Reinhardt, J.; Sigles, W.R.; editores). Geological Society of America, Special Paper 216: 1-20.
Salfity, J.A.; Gorustovich, J.A. 1983. Paleogeografía de la cuenca del Grupo Paganzo (Paleozoico superior). Revista de la Asociación Geológica Argentina 38 (3-4): 437-453.

Soil Survey Staff. 1999. Soil Taxonomy: A Basic System of Soil Classification for Making and Interpreting Soil Surveys. Agriculture Handbook, USDA Natural Resources Conservation Service: 869 p. Washington DC.

Spalletti, L.A.; Limarino, C.O. 2017. The Choiyoi magmatism in south western Gondwana: implications for the end-permian mass extinction-a review. Andean Geology 44: 328-338. doi: 10.5027/andgeoV44n3-a05.

Spalletti, L.A.; Limarino, C.O.; Colombo Piñol, F. 2010. Aeolian fluvial interaction systems from the de La Cuesta Formation (Permian), Sierra de Narváez (northwestern Argentina). Geologica Acta 8 (4): 431-447.

Stappenbeck, R. 1910. La Precordillera de San Juan y Mendoza. Anales del Ministerio de Agricultura, Sección Geología, Mineralogía y Minería 4 (3): 1-187. Buenos Aires.

Tankard, A.J.; Hobday, D.K. 1977. Tide-dominated backbarrier sedimentation, early Ordovician Cape Basin, Cape Peninsula, South Africa. Sedimentary Geology 18 (1-3): 135-159.

Tiwari, R.S. 1973. Scheuringipollenites, a new name for the Gondwana sporomorphs so far assigned to "Sulcatisporites Leschik 1955". Senckenbergiana Lethaea 54: 105-117.

Tripaldi, A.; Limarino, C.O. 2008. Ambientes de interacción eólica-fluvial en valles intermontanos: ejemplos actuales y antiguos. Latin American Journal of sedimentology and Basin Analysis 15 (1): 43-66.

Tschudy, R.H.; Kosanke, R.M. 1966. Early Permian vesiculate pollen from Texas, USA. The Palaeobotanist 1: 59-72.

Ybert, J.P.; Marques-Toigo, M. 1971. Polarisaccites nov. gen. Pollen et Spores 12: 468-481.

Manuscript received: July 26, 2019; revised/accepted: August 27, 2020; available online: January 29, 2021. 